\title{
STAREA ACTUALĂ A FITOPLANCTONULUI ȘI ZOOPLANCTONULUI RÂULUI BÂC
}

\author{
Tumanova Daria, Lebedenco Liubovi, Ungureanu Grigore \\ Institutul de Zoologie al MECC, Chișinău, Republica Moldova, str. Academiei 1 \\ e-mail: dariatumanova@gmail.com
}

https://doi.org/10.53937/9789975315975.83

\begin{abstract}
The article presents the results of the investigations on diversity and quantitative structure of phytoplankton and zooplankton of the Bâc River during spring 2018. The phytoplankton composition of the Bâc River consisted of 44 species. The following phytoplankton groups were predominating: Cyanophyta, Bacillariophyta, Chlorophyta and Euglenophyta. The zooplankton species were presented by Rotatoria, Copepoda and Cladocera taxonimic grups and consisted of 8 taxonomic units. The highest values in the number of species and biomass were estimated downstream of Calarash town. The values of saprobic indices were in proportion of $62 \%$, thus belonging typically to $\beta$-mezosaprobic. Such values indicated that the water quality was attributed mainly to III-rd (moderately polluted) quality class.
\end{abstract}

Key words: phytoplankton, zooplankton, Bâc River, water quality

\section{INTRODUCERE}

Problema stării ecologice a ecosistemelor acvatice din Republica Moldova este una de mare actualitate. Râurile mici sunt cele mai numeroase cursuri de apă și joacă un rol deosebit de important. Comunitățile de hidrobionți care se dezvoltă în râurile mici sunt foarte sensibile la schimbarea condițiilor de mediu. Râul Bîc este unul dintre principalii afluenți ai fluviului Nistru cu o lungime de 155 km și traversează numeroase localități situate în 4 raioane (Călărași, Strășeni, Anenii Noi, laloveni) și mun. Chișinău. Râul Bâc nu este doar un flux natural de apă, care satisface necesitățile vitale ale populației din regiune, dar și un colector de ape reziduale care provin din localitaţile amplasate pe malurile acestuia. Numărul mare de localități, dezvoltarea producției industriale și agricole de-a lungul râului Bâc, absența stațiilor de epurare a apelor industriale și menajere, au dus la deversarea directă a apelor uzate în râu, ceea ce cauzează poluarea râului 
și respectiv a fluviului Nistru $[3 ; 5 ; 6]$. Poluarea apei cu diferiţi compuși chimici provoacă eutrofizarea excesivă a ecosistemelor acvatice, care duce la schimbări rapide ale proprietăţilor fizico-chimice ale apei. Hidrobionţii reacţionează rapid la schimbările condiţiilor ecologice și sunt bioindicatori cu o sensibilitate înaltă faţă de modificările fizico-chimice ale mediului și a gradului de încărcare organică. Poluarea antropică a mediului acvatic este una dintre problemele globale de mediu ale societăţii moderne, și este probabil cel mai important factor de mediu care influenţează organismele acvatice și ecosistemele în întregime.

Evaluarea diversităţii specifice, structurii cantitative, funcționării comunităților de hidrobionți și evoluţiei calităţii apei râului Bâc au o importanță deosebită în contextul aprecierii contribuției acestora la formarea calității apei fl. Nistru, care reprezintă sursa principală de aprovizionare cu apă a Republicii Moldova [1, 2, 3].

\section{MATERIALE ȘI METODE}

Pentru realizarea investigatiilor au fost efectuate expediţii în teren, pe r. Bâc (9 staţii de colectare - Călărași amonte, aval; Strășeni amonte, aval; Chișinău amonte, aval și 3 staţii la confluenţa cu fl. Nistru).

Colectarea probelor și analiza lor în laborator a fost efectuată conform metodelor clasice hidrobiologice [1, 2, 3, 4]. Probele fito- și zooplanctonice au fost colectate în perioada estivală a anului 2018. Determinarea parametrilor cantitativi ai comunităților planctonice (fito- și zooplankton) a fost realizată prin metode acceptate în hidrobiologie și standardele ISO [2, 4]. Identificarea hidrobionților și analiza cantitativă a fost efectuată cu ajutorul microscopului Lomo "MICMED 2" și microscopului Axio Imager A.2 (Zeiss) cu utilizarea determinatoarelor și literatura de specialitate $[7,8,9]$. Eșantioanele hidrobiologice au fost prelevate din biotopuri reprezentative în cadrul cercetărilor Laboratorului de Hidrobiologie și Ecotoxicologie ale Institutului de Zoologie al MECC.

\section{REZULTATE ȘI DISCUŢII}

Fitoplanctonul râului Bâc a fost reprezentat de 44 specii și varietăţi de alge planctonice care se referă la 4 grupe taxonomice: Cyanophyta -4 , Bacillariophyta - 22, Euglenophyta - 9, Chlorophyta - 9. Mai frecvent întâl- 
nite au fost algele cianofite, bacilariofite și algele verzi dintre care cele mai frecvente au fost: Aphanizomenon flos-aquae (L.)Ralfs f.flos-aquae, OsciIlatoria planctonica, Cyclotella kuetzinghiana, Gomphonema olivaceum, Navicula cryptocephala, Nitzschia acicularis, Nitzschia sigmoidea, Synedra ulna, Euglena polymorpha.

Valorile efectivului numeric al fitoplanctonului r.Bâc a variat în limitele 0,79-20,58 mln cel./l. Cele mai ridicate valori au fost atestate la staţia Calarași, în aval, cauzate de dezvoltarea cianofitelor $-5,73 \mathrm{mln}$ cel./l, euglenofitelor-1,73 mln cel.// și clorofitelor -12,26 mln cel./l. Biomasa ridicată la această staţie a fost cauzată de prezenţa algelor euglenofite -12,98 g/ $\mathrm{m}^{3}$, care au masa individuală mare (Fig.1). Valorile biomasei fitoplanctonului au variat în limitele 1,14 -21,09 $\mathrm{g} / \mathrm{m}^{3}$. Conform valorilor biomasei fitoplanctonului, râul Bâc se referă în majoritatea cazurilor la categoria de troficitate "eutrof", uneori „politrof". Pe tot cursul râului Bâc au fost atestate specii din grupul Euglenophyta care sunt buni indicatori ai calităţii apei.

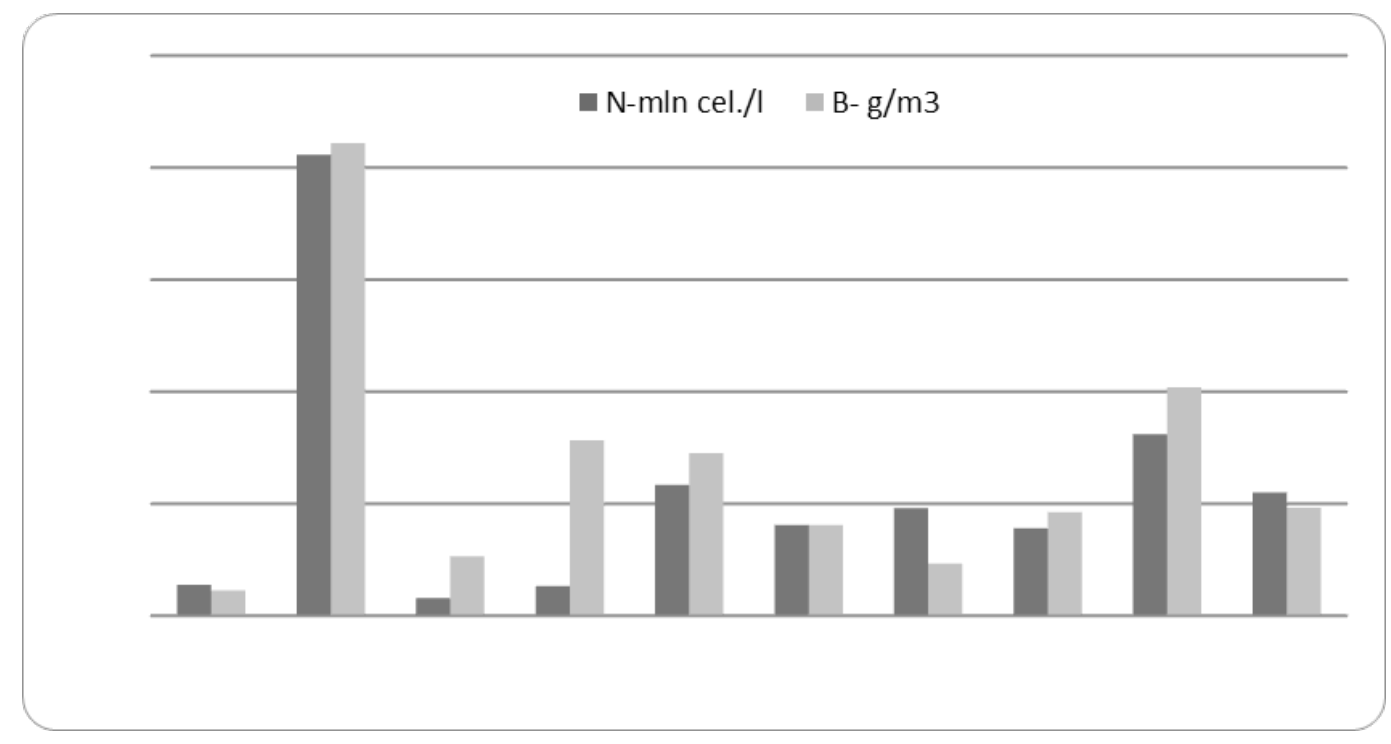

Fig ura 1. Efectivul ( $N$ - $\mathrm{mln}$ cel./l) şi biomasa $\left(B-\mathrm{g} / \mathrm{m}^{3}\right)$ fitoplanctonului r.Bâc (1- Calarasi amonte, 2- Călărași aval, 3- Străşeni amonte, 4-Straşeni aval, 5- Chişinău amonte, 6 -Chişinău aval, 7- Anenii Noi, 8- fl. Nistru amonte de r. Bâc, 9- r. Bâc, până la confluență, 10- fl. Nistru, aval de confluența cu r. Bâc). 
Din numărul total de specii de alge, 34 sunt specii indicatoare ale saprobităţii apei. Cele mai multe dintre ele, ce constituie $62 \%$ sunt specii $\beta$-mesosaprobe, dintre care cele mai frecvent întâlnite au fost: Aphanizomenon flos-aquae, Cyclotella kuetzinghiana, Euglena acus, Phacus pleuronectes, Trachelomonas hispida. Speciile -mesosaprobe au constituit $12 \%$ la care se referă: Navicula cryptocephala, Navicula pygmaea, Nitzschia acicularis, Nitzschia palea, Hantzschia amphioxis, Euglena polymorpha. Au fost atestate specii cu preferenţă la zona polisaprobă (Euglena viridis, Chlorella vulgaris) și xenosaprobă (Fragilaria virescens) (Fig.2.).

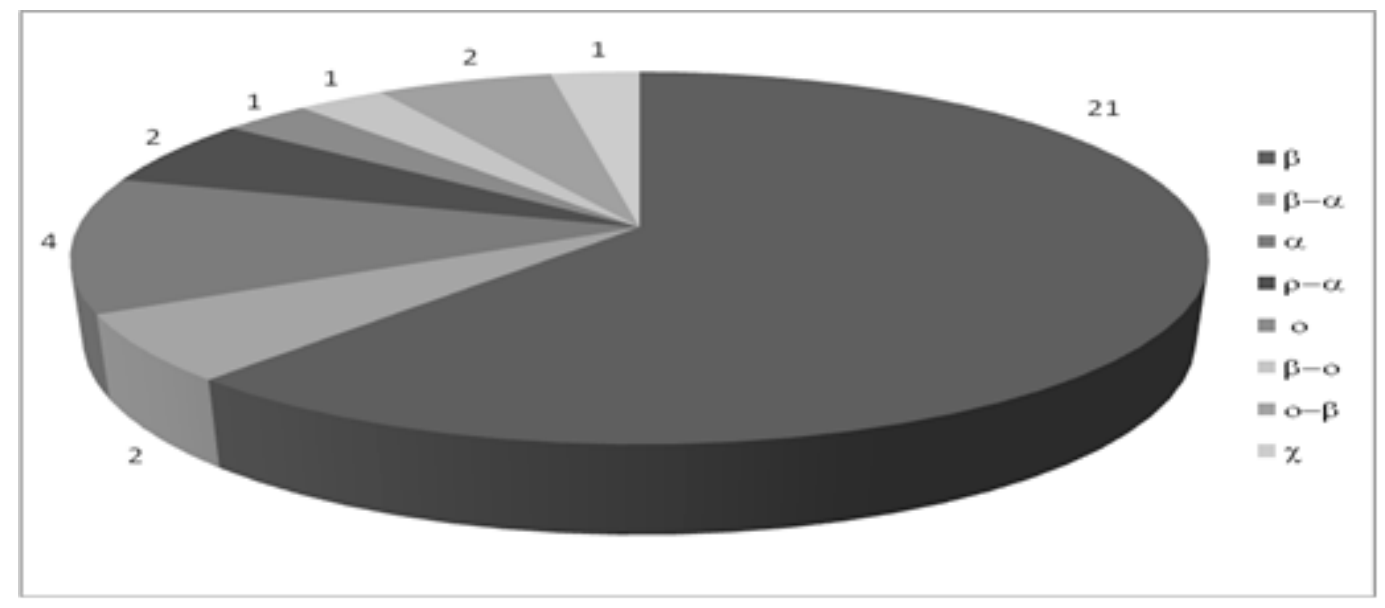

Figura 2. Distribuirea speciilor indicatoare din componenta fitoplanctonului râul Bâc în zonele de saprobitate în perioada de primăvară a anului 2018.

În râul Bâc în perioada de primăvară, 2018 predominau speciile $\beta$-mesosaprobe, valorile indicelui saprobic variind între 1,61-2,63, și încadrâdu-se în limitele claselor calităţii apei III-a (moderat poluată).

Dezvoltarea zooplanctonului, râului Bâc este foarte puțin studiată, fiind reflectate în literatura de specialitate doar unele date sporadice. Conform analizelor hidrobiologice, efectuate de către Serviciului Hidrometeorologic de Stat, ecosistemul râului Bâc corespunde claselor de calitate a apei III -IV (moderat poluată - degradată) [3]. Datorită sensibilității 
și reacției rapide la fluctuațiile factorilor de mediu, speciile din componența zooplanctonului râurilor mici sunt foarte valoroase în monitorizarea stării ecosistemelor acvatice.

În perioada estivală a anului 2018 zooplanctonul râului Bâc a fost prezentat de rotifere (Rotatoria) și crustacee (Copepoda, Cladocera).

Tabelul 1. Componenţa specifică și efectivul $\left(\mathrm{N}-\mathrm{ind} / \mathrm{m}^{3}\right)$ zooplanctonului râului Bâc.

\begin{tabular}{|l|l|l|}
\hline Grupe & Unități taxonomice & $\mathbf{N}, \mathbf{i n d} / \mathbf{m} \mathbf{3}$ \\
\hline Rotatoria & Asplanchna priodonta & 100 \\
\hline \multirow{3}{*}{ Copepoda } & Brachionus nilsoni & 147 \\
\cline { 2 - 3 } & Rotaria rotatoria & 900 \\
\hline & Copepodit Cyclopoida & 440 \\
\cline { 2 - 3 } & Eucyclops serrulatus & 147 \\
\cline { 2 - 3 } & Nauplii Cyclopoida & 293 \\
\cline { 2 - 3 } & Thermocyclops crassus & 100 \\
\hline Cladocera & Ceriodaphnia pulchella & 293 \\
\hline Total & & $\mathbf{2 4 2 0}$ \\
\hline
\end{tabular}

Diversitatea specifică a zooplanctonului a înregistrat în total 8 unităţi taxonomice, dintre care 6 specii și stadii de dezvoltare a copepodelor. În componența zooplanctonului râului Bâc, rotiferele au fost formate din 3 specii (Asplanchna priodonta, Brachionus nilsoni, Rotaria rotatoria), 2 specii de copepode (Eucyclops serrulatus, Thermocyclops crassus) și stadii de dezvoltarea a acestora (Tab.1). Cladocerele au fost prezentate de o singură specie - Ceriodaphnia pulchella. Complexul dominant a fost constituit din specia Rotaria rotatoria și stadiile juvenile ale copepodelor. Dezvoltarea cantitativă a comunităților zooplanctonice ale râului Bâc este foarte modestă, efectivului numeric constituind $2420 \mathrm{ind} / \mathrm{m}^{3}$ iar biomasa $-24,67 \mathrm{mg} / \mathrm{m}^{3}$. Din datele obținute și prezentate în figura 1 se constată aportul principal al rotiferelor în formarea efectivului zooplanctonului și al crustaceelor in formarea biomasei, ceea ce reprezintă un fenomen tipic pentru ecosistemele din republică. 
Trebuie de menționat majorarea efectivului numeric al zooplanctonului pe cursul râului până la zona de confluență cu fl. Nistru. Astfel, în sectorul varsării râului Bâc în fluviul Nistru, efectivul numeric a constituit $1320 \mathrm{ind} / \mathrm{m}^{3}$ cu biomasa 19,14 mg/m³ , iar la st. Anenii Noi valorile efectivului și biomasei zooplanctonului au fost $1100 \mathrm{ind} / \mathrm{m}^{3}$ și $5,53 \mathrm{mg} / \mathrm{m}^{3}$ respectiv (Fig.3.). Acesta denotă capacitatea de autoepurarea a ecosistemului și rolul comunităților planctonice filtratoare (rotiferele, cladocerele etc.) în funcționarea acestuia.

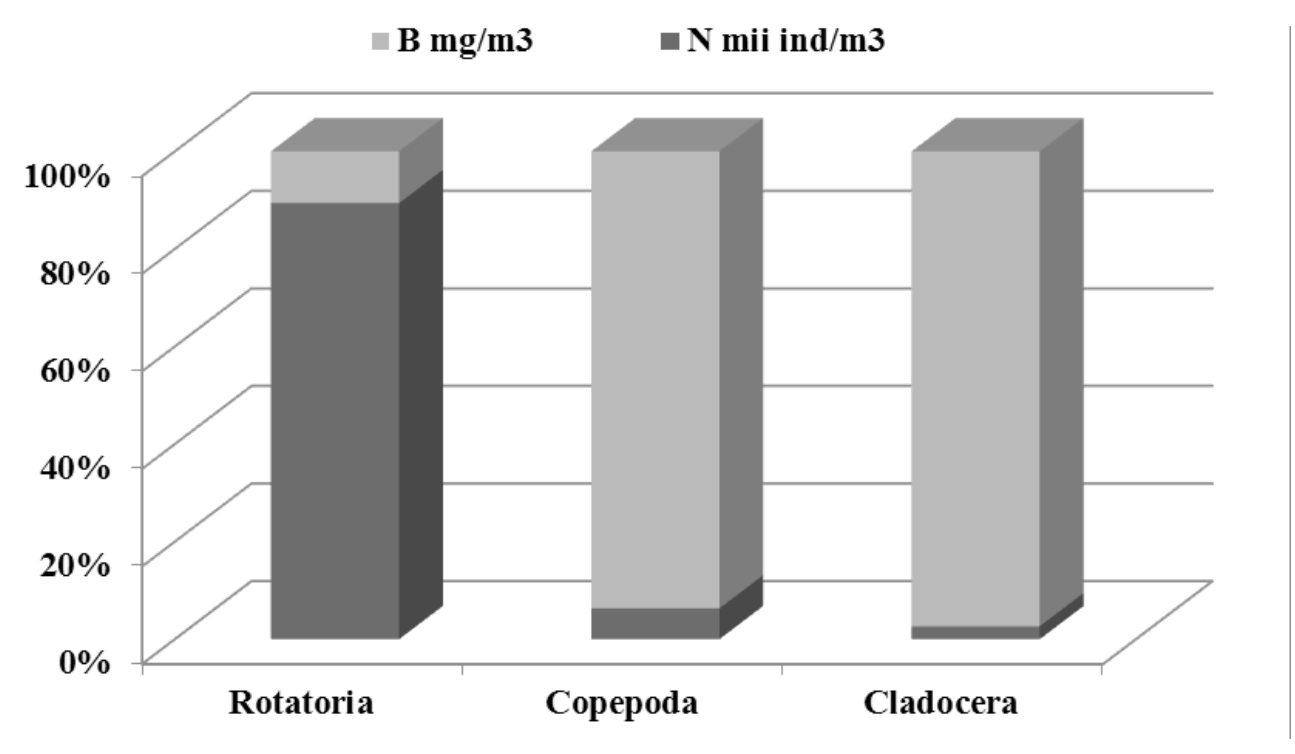

Figura. 3 Aportul principalelor grupe zooplanctonice în formarea efectivului numeric și biomasei râului Bâc în primăvara anului 2018.

Speciile înregistrate în ecosistemul râului Bâc sunt în majoritate specii cosmopolite, care se rferă la zonele de saprobitate oligo-betamezosaprobă și polisaprobă. Prezența și abundența $\left(900\right.$ ind $\left./ \mathrm{m}^{3}\right)$ speciei Rotaria rotatoria cu preferință față de zona polisaprobă și indicele de saprobitate 3,25 relevă poluarea ecosistemului investigat.

Calitatea apei se modifică pe cursul râului în dependență de sursele de poluare, iar valorile indicelui de saprobitate au variat în limitele 1,51 3,19. Astfel, in apropierea orașului Anenii Noi, indicele saprobic, calculat 
conform parametrilor cantitativi ai zooplanctonului a constituit 3,19 și se încadrează în limitele clasei a IV " poluată".

Calitatea apei râului Bâc în perioada de primăvară a anului 2018 conform indicelui de saprobitate mediu $(2,35)$ calculat în baza parametrilor cantitativi ai zooplanctonului se atribuie clasei III de calitate "moderat poluată".

\section{CONCLUZII}

În perioada investigaţiilor în componenţa fitoplanctonului au fost identificate 44 specii și varietăţi de alge planctonice care se referă la 4 grupe taxonomice: Cyanophyta -4, Bacillariophyta - 22, Euglenophyta 9, Chlorophyta - 9.

Valorile efectivului numeric al fitoplanctonului r.Bâc a variat în limitele 0,79-20,58 $\mathrm{mln}$ cel./I, iar biomasei 1,14-21,09 g/m³. Conform valorilor biomasei fitoplanctonului r.Bâc poate fi atribuit categoriei ecosistemelor eutrofe, periodic politrofe.

Conform valorilor indicelui saprobic al fitoplanctonului, calitatea apei în râul Bâc se încadrează în limitele clasei III (moderat poluată).

Diversitatea specifică a zooplanctonului râului Bâc a înregistrat în total 8 unităţi taxonomice dintre care 3 aparținând rotiferelor, 4 - copepodelor și 1 - cladocerelor. E de menționat că componența și dezvoltarea comunităţilor zooplanctonice din ecosistemul râului Bâc este scazută din cauza poluării considerabile a râului cu scurgeri superfeciale ale apelor uzate menajere și de producere neepurate și nu in ultimul rind a debitului mic sau chiar a secării în unele perioade. Calitatea apei din ecosistemul râului Bâc în perioada sezonului de primăvara a anului 2018, conform indicelui mediu de saprobitate $(2,35)$ a comunităților zooplanctonice se atribuie clasei III de calitate "moderat poluată".

Investigaţiile au fost efectuate în cadrul proiectului pentru tineri cercetători: 18.80012.50.21A. 


\section{BIBLIOGRAFIE}

1. Ghid de prelevare a probelor hidrochimice și hidrobiologice. Ed. Toderaș I. et al. Chișinău: Elan Poligraf, 2015. p. 64.

2. Lebedenco L., Jurminskaia O. Zooplancton. În: Toderaș I., Zubcov E., Bilețchi L. (red.) Monitoringul calității apei și evaluarea stării ecologice a ecosistemelor acvatice. Îndrumar metodic. Institutul de Zoologie, AȘM, Chișinău, 2015, 51-57.

3. Raport anual. Starea calității apelor de suprafață conform elementelor hidrobiologice pe teritoriul Republicii Moldova în anul 2015. Chișinău: Ministerul Mediului al Republicii Moldova, Serviciul Hidrometeorologic de Stat. 2016. p. 169-173.

4. Regulament cu privire la cerinţele de calitate a mediului pentru apele de suprafaţă. Anexa 1. publicat: 22.11.2013 în Monitorul Oficial Nr.262-267, art. Nr.1006, 2013, p. 32-39.

5. Tumanova D. Algele planctonice-indicatori ai calităţii apei fluviului Nistru. Buletinul Academiei de Știinţe a Moldovei. Seria "Știinţ̧ele vieţii". 2016, 2 (329), p. 95-102.

6. Ungureanu L., Tumanova D. Calitatea apei ecosistemelor acvatice principale ale bazinului fluviului Nistru. În: Buletinul Academiei de Știinţe a Moldovei. Știinţele vieţii. Chișinău 2010, N 3 (312), p. 101 - 110. ISSN 1857-064X.

7. Храмцов А. К. Краткое руководство по определению родов пресноводных водорослей. - Минск, 2004., 49 с.

8. Оксиюк О.П. Оценка водных объектов Украины по гидробиологическим показателям. ГиАробиол.журн., Т.30, № 3, 1994, 26-31 с.

9. Определитель зоопланктона и зообентоса пресных вод Европейской России. Том 1. Зоопланктон / РеА. Алексеев В. Р. М.-СПб.: Товарещество научных изданий, 2010. Р - 495. 